\title{
Impact of SARS-CoV-2 on reperfusion therapies for acute ischemic stroke in Lombardy, Italy: the STROKOVID network
}

\author{
Alessandro Pezzini ${ }^{1}\left[\right.$ D Mario Grassi ${ }^{2} \cdot$ Giorgio Silvestrelli $^{3} \cdot$ Martina Locatelli ${ }^{1,4} \cdot$ Nicola Rifino ${ }^{5,16}$. \\ Simone Beretta ${ }^{5,16} \cdot$ Massimo Gamba $^{6}$. Elisa Raimondi ${ }^{7} \cdot$ Giuditta Giussani $^{8} \cdot$ Federico Carimati $^{9} \cdot$ Davide Sangalli $^{10}$. \\ Manuel Corato ${ }^{11}$. Simonetta Gerevini ${ }^{12}$. Stefano Masciocchi ${ }^{1} \cdot$ Matteo Cortinovis $^{1} \cdot$ Sara La Gioia ${ }^{13}$. \\ Francesca Barbieri ${ }^{3}$. Valentina Mazzoleni ${ }^{1}$. Debora Pezzini ${ }^{1}$. Sonia Bonacina ${ }^{1}$ - Andrea Pilotto ${ }^{1} \cdot$ Alberto Benussi $^{1}$. \\ Mauro Magoni ${ }^{6}$. Enrico Premi ${ }^{6}$. Alessandro Cesare Prelle ${ }^{7}$. Elio Clemente Agostoni ${ }^{8}$. Fernando Palluzzi ${ }^{2}$. \\ Valeria De Giuli ${ }^{4} \cdot$ Anna Magherini $^{3} \cdot$ Daria Valeria Roccatagliata $^{3} \cdot$ Luisa Vinciguerra $^{4} \cdot$ Valentina Puglisi $^{4}$. \\ Laura Fusi ${ }^{14}$. Rubjona Xhani ${ }^{14}$. Federico Pozzi ${ }^{14}$. Susanna Diamanti ${ }^{5,16}$. Francesco Santangelo ${ }^{5,16}$. \\ Giampiero Grampa ${ }^{14}$. Maurizio Versino ${ }^{9} \cdot$ Andrea Salmaggi $^{10}$. Simona Marcheselli ${ }^{11}$. Anna Cavallini ${ }^{15}$. \\ Alessia Giossi ${ }^{4} \cdot$ Bruno Censori $^{4}$ - Carlo Ferrarese ${ }^{5,16} \cdot$ Alfonso Ciccone $^{3} \cdot$ Maria Sessa $^{13} \cdot$ Alessandro Padovani $^{1}$ on \\ behalf of the STROKOVID group
}

Received: 3 November 2020 / Revised: 22 February 2021 / Accepted: 24 February 2021 / Published online: 8 March 2021 (c) Springer-Verlag GmbH, DE part of Springer Nature 2021

\begin{abstract}
Whether and how SARS-CoV-2 outbreak affected in-hospital acute stroke care system is still matter of debate. In the setting of the STROKOVID network, a collaborative project between the ten centers designed as hubs for the treatment of acute stroke during SARS-CoV-2 outbreak in Lombardy, Italy, we retrospectively compared clinical features and process measures of patients with confirmed infection (COVID-19) and non-infected patients (non-COVID-19) who underwent reperfusion therapies for acute ischemic stroke. Between March 8 and April 30, 2020, 296 consecutive patients [median age, 74 years (interquartile range (IQR), 62-80.75); males, 154 (52.0\%); 34 (11.5\%) COVID-19] qualified for the analysis. Time from symptoms onset to treatment was longer in the COVID-19 group [230 (IQR 200.5-270) minutes vs. 190 (IQR 150-245) minutes; $p=0.007$ ], especially in the first half of the study period. Patients with COVID-19 who underwent endovascular thrombectomy had more frequently absent collaterals or collaterals filling $\leq 50 \%$ of the occluded territory $(50.0 \%$ vs. $16.6 \%$; OR 5.05; 95\% CI 1.82-13.80) and a lower rate of good/complete recanalization of the primary arterial occlusive lesion (55.6\% vs. 81.0\%; OR 0.29; 95\% CI 0.10-0.80). Post-procedural intracranial hemorrhages were more frequent (35.3\% vs. 19.5\%; OR 2.24; 95\% CI 1.04-4.83) and outcome was worse among COVID-19 patients (in-hospital death, $38.2 \%$ vs. 8.8\%; OR 6.43; 95\% CI 2.85-14.50). Our findings showed longer delays in the intra-hospital management of acute ischemic stroke in COVID-19 patients, especially in the early phase of the outbreak, that likely impacted patients outcome and should be the target of future interventions.
\end{abstract}

Keywords Coronavirus disease $\cdot$ Public health $\cdot$ Stroke

\section{Introduction}

With more than 17,600 deaths out of a population of approximately 10 million inhabitants [1], the Lombardy region, located in Northern Italy, is one of the areas most severely hit by SARS-CoV-2 since the very beginning of the

Alessandro Pezzini

ale_pezzini@hotmail.com

Extended author information available on the last page of the article pandemic. Since the outbreak begun, specific measures have been taken to contain the spread of the disease, including locking down the communities, converting general medical wards to quarantine wards, and reorganizing in-hospital clinical activities with plans for the emergency management and treatment of acute conditions. One such measure has been to concentrate a large majority of acute stroke patients in a limited number of hospitals [2]. Whether this had an influence on timely reperfusion strategies for acute brain ischemia is currently unknown. 


\section{Materials and methods}

\section{Study group}

Data were collected in the setting of a prospective, hospital-based, multicentre study conducted in Lombardy, Northern Italy. Because of the spread of the epidemic, on March 8, 2020, the Lombardy regional government passed a deliberation to reduce to ten hospitals with catheterization facilities for the treatment of acute ischemic stroke acting as hubs, with the remaining hospitals acting as spokes, on the basis of geographic proximity. Since these ten centers were designated hospitals for transfer of patients from the contiguous catchment area at the early stage of the outbreak, this implicates that all patients with suspected or proven acute stroke-regardless of whether they were eligible for acute reperfusion therapy-were transferred from the spokes to the ten hubs, which, therefore, became in charge of the management of all acute strokes in the Lombardy region during the study period. The STROKOVID network is a joint initiative of these ten hub centers, which is expected to provide comprehensive information on patients hospitalized for acute ischemic stroke in Lombardy during SARS-CoV-2 outbreak and to address clinical research questions. In the present retrospective analysis, we investigated the impact of infection on reperfusion therapies for acute brain ischemia and inhospital patients outcome in a cohort of patients admitted between March 8 and April 30, 2020. Individual data from all patients who received reperfusion therapies during the study period were collected with a standardized form with predefined variables. Local study investigators completed the forms systematically using prospectively ascertained in-hospital ischemic stroke registries. Completed forms from all centres were compiled in the coordinating centre Brescia, where the analysis of the pooled data was performed. The Institutional Ethical Standards Committee on human experimentation of the ASST Spedali Civili University Hospital, Brescia approved this analysis (Institutional Review Board number: NP 4051) and each study center provided approval for the study. The study was conducted in accordance with the Declaration of Helsinki. All included patients gave their written informed consent on admission for data collection and publication of deidentified data.

\section{Risk factor definition}

Hypertension was defined as systolic blood pressure $140 \mathrm{~mm} \mathrm{Hg}$ or higher and diastolic pressure $90 \mathrm{~mm} \mathrm{Hg}$ or higher in two separate measurements after the acute phase or use of antihypertensive drugs before recruitment; diabetes, with a history of diabetes, use of a hypoglycemic agent or insulin, or fasting glucose level $126 \mathrm{mg} / \mathrm{dL}$ or higher; current smoking, including former smokers who had quit smoking for 2 years before the index event; hypercholesterolemia, with cholesterol serum levels $220 \mathrm{mg} /$ $\mathrm{dL}$ or higher or use of cholesterol lowering drugs. Body mass index (BMI) was calculated as weight in kilograms divided by the square of the height in meters $\left(\mathrm{kg} / \mathrm{m}^{2}\right)$. All patients underwent continuous cardiac monitoring using standard bedside monitors immediately after SU admission. In those patients who had not received a diagnosis before the index stroke, atrial fibrillation (AF) was eventually diagnosed by a cardiologist based on the ECGs performed in the emergency room with patients in a supine position using standard, 10-s, 12-lead ECG devices, as well as on the ECG recordings performed during hospital stay. We also collected information on history of coronary ischemic heart disease (myocardial infarction, history of angina, or existence of multiple lesions on thallium heart isotope scan or evidence of coronary disease on coronary angiography), previous ischemic stroke (based on clinical history or medical records), and pre-stroke medications (in particular, warfarin, aspirin or other antiplatelet agents, antihypertensive agents, oral hypoglycemic agents or insulin, and statins).

\section{Neurovascular assessment and procedures}

Patients received an initial diagnostic evaluation and treatment based on established guidelines [3]. All patients were classified into etiologic subgroups according to the Trial of ORG 10,172 in Acute Stroke Treatment criteria [4] by local investigators at each study center. Initial stroke severity was assessed by the National Institutes of Health Stroke Scale score [5]. Early ischemic changes were quantified using the Alberta Stroke Program Early CT Score (ASPECTS) [6, 7] on baseline CT. We systematically assessed the following variables: modified Rankin Scale score [8] before stroke (pre-stroke mRS), blood pressure values on admission before any stroke therapy, time from stroke symptoms onset to hospital admission, time from stroke symptoms onset to baseline brain imaging, and, in patients who received endovascular recanalization therapy, time from stroke symptoms onset to treatment and time from femoral puncture to recanalization. When indicated, cerebral large-artery occlusion was confirmed by head and neck CT angiography. Patients who were deemed eligible, received intravenous thrombolysis or endovascular mechanical thrombectomy or a combined treatment with full-dose intravenous rtPA and "contemporary/as soon as possible" endovascular mechanical thrombectomy [3]. Any decision on the technique and the specific device for endovascular thrombectomy was left to the discretion of 
the neurointerventionalist in charge of the patient in each centre. For middle cerebral artery (MCA) occlusion, the collateral circulation was scored on a $0-3$ points scale. A score of 0 indicated absent collateral supply to the occluded MCA territory. A score of 1 indicated collateral supply filling $\leq 50 \%$ but $>0 \%$ of the occluded MCA territory. A score of 2 was given for collateral supply filling $>50 \%$ but $<100 \%$ of the occluded MCA territory. A score of 3 was given for $100 \%$ collateral supply of the occluded MCA territory [9]. After treatment, recanalization grade was assessed on digital subtraction angiography based on the Thrombolysis in Cerebral Infarction (TICI) scale, considering grades $2 \mathrm{~b}$ and 3 , as good recanalization [10]. Intracerebral hemorrhage was any intracerebral bleeding detected at follow up noncontrast CT performed during hospital stay. Symptomatic intracerebral hemorrhage (sICH) was defined according to the European Cooperative Acute Stroke Study III (ECASS III) criteria [11].

\section{Laboratory procedures}

All patients admitted to the participating hospitals were tested for SARS-CoV-2 infection by RT PCR procedure on throat-swab and nasopharyngeal specimens [12]. In case of high clinical suspicion of SARS-CoV-2 infection and negative test results on two nasopharyngeal and oropharyngeal swabs performed at least $24 \mathrm{~h}$ apart, testing of lower respiratory samples (bronchoalveolar lavage fluid obtained by bronchoscopy) was performed.

\section{Statistical analysis}

We compared the characteristics of patients with positive SARS-CoV-2 nucleic acid test (COVID-19) with those of patients with negative test result (non-COVID-19). For subgroup comparisons, we used the $\chi^{2}$ test or the Fisher exact test, and the Mann-Whitney $U$ test, when appropriate. Results are given as odds ratio with $95 \%$ CI. $p \leq 0.05$ on twosided test was considered significant. Data were analyzed using the SPSS (version 21.0) package (www.spss.com).

\section{Results}

During the study period, 296 subjects [median age, 74 (IQR 62-80.75) years; males, 154 (52.0\%)] qualified for the analysis. Of these, 115 (38.9\%) received intravenous thrombolysis, 103 (34.8\%) endovascular thrombectomy, and 78 (26.4\%) combined therapy. Thirty-four patients (11.5\%) tested positive for SARS-CoV-2 infection, which preceded the occurrence of stroke in all the cases. Their prevalence in the first half of the study period (15.3\%, 8 March to 3 April, $2020)$ outnumbered that in the second half $(6.8 \%, 4$ April to 30 April, 2020; OR 2.49; 95\% CI 1.12-5.55). Overall, patients with confirmed infection did not differ from nonCOVID-19 patients, except for an increased prevalence of males and a higher frequency of atrial fibrillation. We found no difference in the time interval between stroke symptoms onset and hospital admission, as well as between stroke symptoms onset to baseline brain imaging. Conversely, the time from stroke symptoms onset to treatment (onset-to-needle in those who received intravenous thrombolysis or combined therapy; onset-to-groin puncture in those who received endovascular thrombectomy) was a median of 40 min longer in the COVID-19 group (Table 1).

Such difference was consistent between the two treatment subgroups (Table 2), but it was significantly longer only in the first half of the study period (Fig. 1).

Among patients who underwent endovascular thrombectomy, the percentage of those with absent collaterals or collaterals filling $\leq 50 \%$ of the occluded territory was higher in the COVID-19 group (50.0\% vs. $16.6 \%$; OR 5.05 ; $95 \%$ CI 1.82-13.80), while that of patients with good/complete recanalization of the primary arterial occlusive lesion was lower (55.6\% vs. $81.0 \%$; OR 0.29 ; 95\% CI $0.10-0.80$; Table 2 and Supplemental Table 1) compared to the subgroup of nonCOVID-19 patients. Finally, post-procedural intracranial hemorrhages were more frequent $(35.3 \%$ vs. $19.5 \%$; OR 2.24; 95\% CI 1.04-4.83), respiratory and medical complications occurred more often (Supplemental Table 2), and, overall, outcome was worse among COVID-19 patients (in-hospital death, $38.2 \%$ vs. $8.8 \%$; OR $6.43 ; 95 \%$ CI 2.85-14.50; Table 3).

\section{Discussion}

Patients with stroke who require hospitalization during SARS-CoV-2 pandemic are at an increased risk of suboptimal outcomes [13]. One factor that might affect outcome in these patients is pre-hospital and in-hospital organization of stroke care system [14, 15], a crucial aspect of stroke management which the STROKOVID collaborative project has the potential to evaluate. Since we found no difference in time from stroke symptoms onset to emergency room arrival, we presume there was a substantial equality in pre-hospital procedures for stroke management in the two groups defined by COVID-19 status. Conversely, a notable result of our analysis is the increased intra-hospital delay in acute stroke treatment of COVID-19 patients, despite no delay in door-to-baseline imaging time. Furthermore, patients with confirmed infection who received endovascular treatment had suboptimal collateral supply to the occluded artery, longer time from groin puncture to recanalization, and decreased reperfusion rates compared to non-infected patients, which likely contributed to the negative outcome. 
Table 1 Demographic and clinical features of the study group according to COVID-19 status

\begin{tabular}{|c|c|c|c|c|}
\hline & COVID-19 $(n=34)$ & Non-COVID-19 $(n=262)$ & Univariable OR (95\% CI) & $p$ value \\
\hline Age, years & $76(63-82.25)$ & $74(61-80)$ & $1.02(0.99-1.05)$ & 0.242 \\
\hline Sex, male & $24(70.6)$ & $130(49.6)$ & $2.43(1.12-5.29)$ & 0.028 \\
\hline Hypertension & $25(73.5)$ & $183(69.8)$ & $1.19(0.53-2.68)$ & 0.659 \\
\hline Diabetes & $5(14.7)$ & $44(16.8)$ & $0.85(0.31-2.39)$ & 1.000 \\
\hline Hypercholesterolemia & $12(35.3)$ & $89(34.0)$ & $1.06(0.50-2.24)$ & 0.850 \\
\hline \multicolumn{5}{|l|}{ Smoking habit } \\
\hline Never smoker & $27(79.4)$ & $168(66.4)$ & 1 & \\
\hline Former smoker & $4(11.8)$ & $36(14.2)$ & $0.69(0.22-2.09)$ & 0.515 \\
\hline Current smoker & $3(8.8)$ & $49(19.4)$ & $0.38(0.11-1.30)$ & 0.125 \\
\hline Coronary heart disease & $7(20.6)$ & $46(17.6)$ & $1.21(0.50-2.96)$ & 0.638 \\
\hline Atrial fibrillation & $12(35.3)$ & $52(19.8)$ & $2.20(1.02-4.73)$ & 0.047 \\
\hline Personal history of ischemic stroke & $3(8.8)$ & $26(9.9)$ & $0.87(0.25-3.07)$ & 1.000 \\
\hline Prior antiplatelets & $12(35.3)$ & $92(35.1)$ & $1.00(0.47-2.12)$ & 0.984 \\
\hline Prior anticoagulants & $5(14.7)$ & $18(6.9)$ & $2.33(0.80-6.76)$ & 0.161 \\
\hline Stroke severity on admission, NIHSS score & $12(7-20.25)$ & $10(6-16)$ & $1.04(0.98-1.09)$ & 0.131 \\
\hline \multicolumn{5}{|l|}{ Cause of stroke } \\
\hline Large-vessel disease & $3(8.8)$ & $55(21.0)$ & $0.33(0.09-1.21)$ & 0.095 \\
\hline Cardiac embolism & $14(41.2)$ & $85(32.4)$ & $1.02(0.46-2.27)$ & 0.950 \\
\hline Small-vessel disease & $1(2.9)$ & $23(8.8)$ & $0.28(0.03-2.26)$ & 0.234 \\
\hline Other determined etiology & $2(5.9)$ & $12(4.6)$ & $1.03(0.20-5.12)$ & 0.966 \\
\hline Undetermined etiology & $14(41.2)$ & $84(32.1)$ & 1 & \\
\hline \multicolumn{5}{|l|}{ Process measures } \\
\hline $\begin{array}{l}\text { Time from stroke onset to hospital admission, minutes, } \\
\text { median (IQR) }\end{array}$ & $84(63-127.5)$ & $90(65-125)$ & & 0.996 \\
\hline $\begin{array}{l}\text { Time from stroke onset to brain imaging, minutes, } \\
\text { median (IQR) }\end{array}$ & $138(112.5-181.5)$ & $131(102.5-178)$ & & 0.389 \\
\hline $\begin{array}{l}\text { Time from stroke onset to treatment, minutes, median } \\
\text { (IQR) }\end{array}$ & $230(200.5-270)$ & $190(150-245)$ & & 0.007 \\
\hline
\end{tabular}

NIHSS National Institute of Health Stroke Scale, IQR interquartile range

Longer intra-hospital delays in stroke treatment, as well as suboptimal performance of endovascular procedures are the putative consequence of the extreme changes in stroke care system. Like many hospitals in China before and in other countries afterwards, Lombardy hospitals implemented stringent infection control measures starting in late February 2020, including full personal protective equipment for stroke team members, along with separated in-hospital acute stroke pathways for COVID-19 and non-COVID-19 patients, and frequent environmental disinfection. The increased concentration of acute stroke patients with confirmed or suspected SARS-CoV-2 infection in a limited number of Hub hospitals likely had a major impact on in-hospital procedures, particularly on timely reperfusion therapies. Alternatively, we cannot exclude that all the efforts implemented to limit the in-hospital diffusion of SARS-CoV-2 infection and to treat COVID-19 might have compromised contemporary standard-of-care for the treatment of acute ischemic stroke, although formal data are lacking to prove this assumption. This likely resulted in inefficient in-hospital transport and delayed medical assessment. Stroke screening and neurological assessment, as well as all the subsequent phases of patient management can be challenging and time consuming when healthcare personnel must comply with personal protection equipment (PPE, masks, eye protection, gowns, and gloves) and other infection control recommendations [16], especially under extreme situations, such as those observed in Lombardy in the early stages of the epidemic. Of course, these protocols are essential for limiting the spread of the infection but also may impact healthcare systems in unexpected ways. Furthermore, at some centers, stroke neurologists were redeployed to other settings to respond to the increasing demands of COVID-19, which might have created a significant gap in care. Uncertainty in administering recanalization therapies in patients with confirmed infection is another potential explanations of our findings. Even after patients arrived in the angiography suite, staff may need more time to wear protective gear and interventional radiologists may not be used to performing mechanical thrombectomy while in full protective equipment, which 
Table 2 Characteristics of acute ischemic stroke patients stratified by reperfusion treatment

\begin{tabular}{|c|c|c|c|c|c|c|c|c|}
\hline & \multicolumn{4}{|c|}{ Endovascular thrombectomy } & \multicolumn{4}{|c|}{ Intravenous thrombolysis } \\
\hline & $\begin{array}{l}\text { COVID-19 } \\
(n=18)\end{array}$ & $\begin{array}{l}\text { Non-COVID-19 } \\
(n=163)\end{array}$ & $\begin{array}{l}\text { Univariable OR } \\
(95 \% \mathrm{CI})\end{array}$ & $p$ value & $\begin{array}{l}\text { COVID-19 } \\
(n=16)\end{array}$ & $\begin{array}{l}\text { Non-COVID-19 } \\
(n=99)\end{array}$ & $\begin{array}{l}\text { Univariable OR } \\
(95 \% \mathrm{CI})\end{array}$ & $p$ value \\
\hline $\begin{array}{l}\text { Age, years, } \\
\text { median (IQR) }\end{array}$ & $78(63-82.5)$ & $73(60-80)$ & $1.02(0.98-1.07)$ & 0.209 & $74(62.75-84.25)$ & $75(61-82)$ & $1.01(0.96-1.05)$ & 0.613 \\
\hline Sex, male & $13(72.2)$ & $76(46.6)$ & $2.97(1.01-8.69)$ & 0.048 & $11(68.8)$ & $54(54.5)$ & $1.83(0.59-5.68)$ & 0.416 \\
\hline $\begin{array}{l}\text { Stroke severity } \\
\text { on admission, } \\
\text { NIHSS score, } \\
\text { median (IQR) }\end{array}$ & $19(8.75-22)$ & $12.5(8-18)$ & $1.06(0.99-1.14)$ & 0.092 & $9(6.25-12.75)$ & $6(4-10)$ & $1.05(0.96-1.14)$ & 0.280 \\
\hline $\begin{array}{l}\text { Systolic blood } \\
\text { pressure on } \\
\text { admission, } \\
\mathrm{mm} \mathrm{Hg}\end{array}$ & $\begin{array}{l}152.5(138.75- \\
170)\end{array}$ & $150(130-165)$ & $1.01(0.98-1.019)$ & 0.898 & $\begin{array}{l}152.5(122.5- \\
167.5)\end{array}$ & $155(140-177.5)$ & $0.98(0.95-1.002)$ & 0.075 \\
\hline $\begin{array}{l}\text { Dyastolic blood } \\
\text { pressure on } \\
\text { admission, } \\
\mathrm{mm} \mathrm{Hg}\end{array}$ & $80(75-100)$ & $80(70-90)$ & $1.00(0.97-1.03)$ & 0.667 & $80(71.25-88.75)$ & $85(74.5-90.25)$ & $0.96(0.92-1.008)$ & 0.110 \\
\hline $\begin{array}{r}\text { ASPECTS on } \\
\text { baseline CT }\end{array}$ & $9(7-10)$ & $9(8-10)$ & $1.04(0.68-1.60)$ & 0.829 & $10(8.5-10)$ & $10(10-10)$ & $0.87(0.59-1.28)$ & 0.285 \\
\hline $\begin{array}{l}\text { Treatment with } \\
\text { rtPA }\end{array}$ & $8(44.4)$ & $70(42.9)$ & $1.06(0.39-2.83)$ & 1.000 & & & & \\
\hline $\begin{array}{l}\text { General anes- } \\
\text { thesia }\end{array}$ & $3(16.7)$ & $35(21.5)$ & $\begin{array}{l}0.73(0.20- \\
2.67)\end{array}$ & 0.768 & & & & \\
\hline \multicolumn{9}{|l|}{ Collateral score } \\
\hline $0-1$ & $9(50.0)$ & $26(16.6)$ & $5.05(1.82-13.80)$ & 0.002 & & & & \\
\hline $\begin{array}{l}\text { No recanaliza- } \\
\text { tion }\end{array}$ & $8(44.4)$ & $31(19.0)$ & $\begin{array}{l}3.40(1.24- \\
9.34)\end{array}$ & 0.029 & & & & \\
\hline $\begin{array}{l}\text { Any intracer- } \\
\text { ebral bleeding }\end{array}$ & $6(33.3)$ & $39(23.9)$ & $\begin{array}{l}1.59(0.56- \\
4.51)\end{array}$ & 0.395 & $6(37.5)$ & $12(12.2)$ & $4.30(1.32-13.97)$ & 0.020 \\
\hline $\begin{array}{l}\text { Symptomatic } \\
\text { intracerebral } \\
\text { bleeding }\end{array}$ & $2(11.1)$ & $11(6.7)$ & $1.72(0.35-8.48)$ & 0.622 & $2(12.5)$ & $5(5.1)$ & $2.65(0.46-15.03)$ & 0.254 \\
\hline $\begin{array}{l}\text { Stroke sever- } \\
\text { ity at } 24 \text { h, } \\
\text { NIHSS score, } \\
\text { median (IQR) }\end{array}$ & $12.5(4.75-19.5)$ & $6(3-14)$ & $1.06(0.99-1.12)$ & 0.054 & $9(3-12)$ & $3(2-7)$ & $1.05(0.99-1.12)$ & 0.073 \\
\hline \multicolumn{9}{|l|}{ Process measures } \\
\hline $\begin{array}{l}\text { Time from } \\
\text { stroke onset } \\
\text { to hospital } \\
\text { admission, } \\
\text { minutes, } \\
\text { median } \\
\text { (IQR) }\end{array}$ & $80(72-138)$ & $83(63-122.5)$ & & 1.000 & $\begin{array}{l}102(59.25- \\
127.5)\end{array}$ & $105(79.25-132)$ & & 0.846 \\
\hline $\begin{array}{l}\text { Time from } \\
\text { stroke onset } \\
\text { to brain } \\
\text { imaging, } \\
\text { minutes, } \\
\text { median } \\
\text { (IQR) }\end{array}$ & $140(108.5-191)$ & $\begin{array}{l}127(99.75- \\
171.75)\end{array}$ & & 0.388 & $136(114-177)$ & $139(110-180)$ & & 0.845 \\
\hline $\begin{array}{l}\text { Time from } \\
\text { stroke onset } \\
\text { to treatment, } \\
\text { minutes, } \\
\text { median } \\
\text { (IQR) }\end{array}$ & $245(207.5-294)$ & ) $194.5(150-255)$ & & 0.034 & $\begin{array}{l}215(184- \\
258.75)\end{array}$ & $185(145-225)$ & & 0.036 \\
\hline
\end{tabular}


Table 2 (continued)

\begin{tabular}{|c|c|c|c|c|c|c|c|c|}
\hline & \multicolumn{4}{|c|}{ Endovascular thrombectomy } & \multicolumn{4}{|c|}{ Intravenous thrombolysis } \\
\hline & $\begin{array}{l}\text { COVID-19 } \\
(n=18)\end{array}$ & $\begin{array}{l}\text { Non-COVID-19 } \\
(n=163)\end{array}$ & $\begin{array}{l}\text { Univariable OR } \\
(95 \% \mathrm{CI})\end{array}$ & $p$ value & $\begin{array}{l}\text { COVID-19 } \\
(n=16)\end{array}$ & $\begin{array}{l}\text { Non-COVID-19 } \\
(n=99)\end{array}$ & $\begin{array}{l}\text { Univariable OR } \\
(95 \% \mathrm{CI})\end{array}$ & $p$ value \\
\hline $\begin{array}{l}\text { Time from } \\
\text { femoral } \\
\text { puncture to } \\
\text { recanaliza- } \\
\text { tion, min- } \\
\text { utes, median } \\
\text { (IQR) }\end{array}$ & $48(36.75-84.25)$ & $31(20-55)$ & & 0.029 & & & & \\
\hline
\end{tabular}

IQR interquartile range, NIHSS National Institute of Health Stroke Scale, ASPECTS Alberta Stroke Program Early CT Score, rt-PA recombinant tissue plasminogen activator

Fig. 1 Time from stroke symptoms onset to treatment according to COVID-19 status in the two study periods

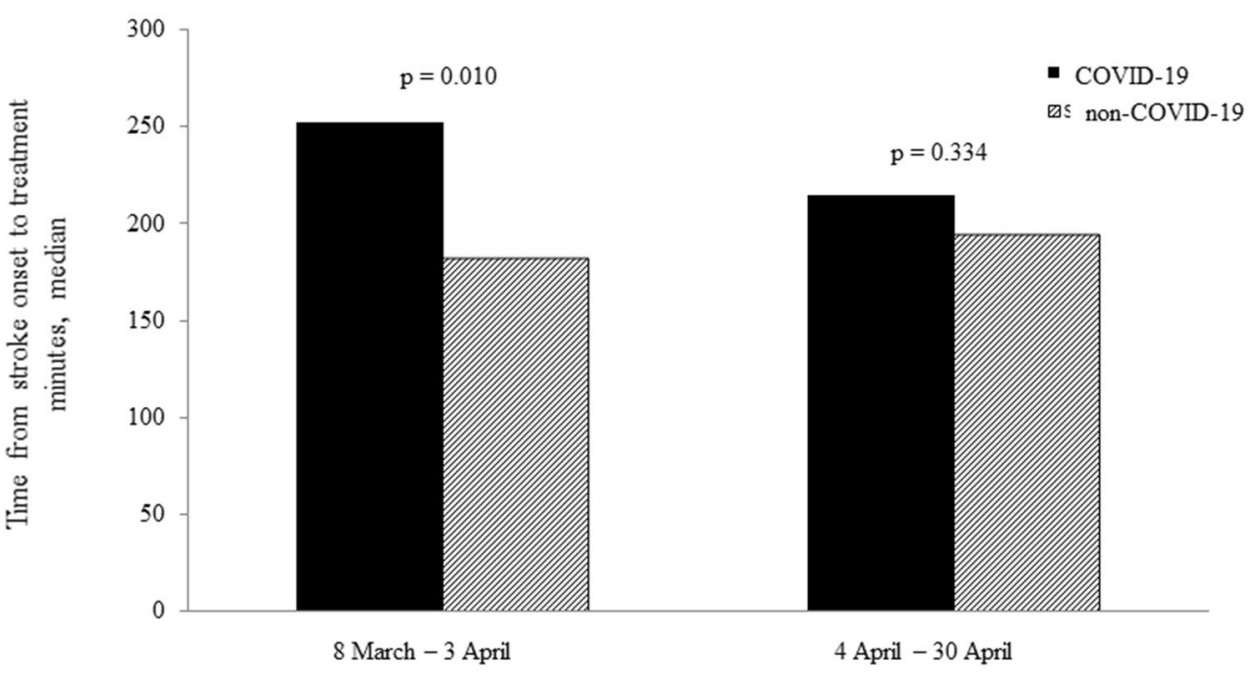

Table 3 In-hospital outcome of acute ischemic stroke patients stratified by COVID-19 status

\begin{tabular}{llccc}
\hline & COVID-19 $(n=34)$ & $\begin{array}{l}\text { Non-COVID-19 } \\
(n=262)\end{array}$ & Univariable OR (95\% CI) \\
\hline Stroke severity at 24 h, NIHSS score & $10(4.5-18.5)$ & $5(2-10)$ & $1.05(1.01-1.10)$ & 0.014 \\
Any intracranial heamorrhage & $12(35.3)$ & $51(19.5)$ & $2.24(1.04-4.83)$ \\
Symptomatic intracranial hemorrhage & $4(11.8)$ & $16(6.1)$ & $2.04(0.64-6.50)$ & 0.035 \\
In-hospital recurrence & $0(0.0)$ & $5(1.9)$ & $0.98(0.96-0.99)$ & 0.265 \\
$\begin{array}{l}\text { Functional independence upon hospital dis- } \\
\quad \text { charge (mRS, 0-2) }\end{array}$ & $9(30.0)$ & $133(56.1)$ & $0.33(0.14-0.76)$ & 0.007 \\
\begin{tabular}{l} 
In-hospital death \\
\hline
\end{tabular}
\end{tabular}

NIHSS National Institute of Health Stroke Scale, functional independence was defined as a score on the modified Rankin scale of 0-2

leads to longer treatment. Whatever the cause of these inhospital delays, they may have contributed, in addition to the hypercoagulable state from systemic inflammation and cytokine storm, postinfectious immune-mediated responses and direct viral-induced endotheliopathy [17], to the lower collateral circulation scoring and recanalization rate we observed in infected patients, though we cannot draw definitive conclusions in this regard, because of the relatively small number of patients who received reperfusion therapies in the present series.

The elucidation of the exact biologic process underlying our findings falls beyond the scope of the present analysis. Nevertheless, the elevated plasma and CSF levels of cytokines in COVID-19 [18], as well as imaging findings, 
which showed meningeal enhancement and diffuse cerebral white matter abnormalities as well as microhemorrhages [19] likely reflect a proinflammatory systemic and brain response. Such inflammatory changes can lead to smallvessel injury, which could also contribute to increase the risk of post-procedural bleeding [20], as suggested by our findings. Notably, these time metrics were significantly affected only in the first half of the study period, probably due to overburdening of the emergency departments, and difficulties in timely clinical evaluations and in-hospital transfer of patients during the epidemic peak, but it cannot be excluded that performances of stroke team members have improved over time as their experience with these protective measures increases.

Therefore, our findings, along with similar observations from other countries [14], emphasize the need to implement plans for intra-hospital stroke management and continuous education and training of healthcare staff to deliver highquality stroke care even during SARS-CoV-2 epidemic.

Supplementary Information The online version contains supplementary material available at https://doi.org/10.1007/s00415-021-10497-7.

Acknowledgements This article is dedicated to Luciano Abruzzi, friend and enthusiastic colleague, who lost his life on April 20th, 2020 fighting against the virus in his beloved city of Cremona.

Funding The STROKOVID project is supported by a grant from Lombardy Region as part of the call "Bando per il finanziamento di progetti di ricerca in ambito sanitario connessi all'emergenza del COVID-19 (DGR N. XI/3017, 30.03.2020)".

\section{Declarations}

Conflict of interest The authors declare that they have no conflict of interest.

\section{References}

1. Ministero della Salute Nuovo coronavirus: cosa c'è da sapere. http://www.salute.gov.it/portale/nuovocoronavirus/ (Accessed November 3, 2020)

2. Stefanini GG, Azzolini E, Condorelli G (2020) Critical organizational issues for cardiologists in the COVID-19 outbreak: a frontline experience from Milan, Italy. Circulation 141:1597-1599

3. Powers WJ, Rabinstein AA, Ackerson T et al (2019) Guidelines for the early management of patients with acute ischemic stroke: 2019 update to the 2018 Guidelines for the Early Management of Acute Ischemic Stroke: a Guideline for Healthcare Professionals From the American Heart Association/American Stroke Association. Stroke 50(12):e344-e418

4. Adams HP Jr, Bendixen BH, Kappelle LJ et al (1993) Classification of subtype of acute ischemic stroke. Definitions for use in a multicenter clinical trial. TOAST. Trial of Org 10172 in Acute Stroke Treatment. Stroke 24:35-41
5. Lyden P, Brott T, Tilley B et al (1994) Improved reliability of the NIH Stroke Scale using video training. NINDS TPA Stroke Study Group Stroke 25:2220-2226

6. Barber PA, Demchuk AM, Zhang J et al (2000) Validity and reliability of a quantitative computed tomography score in predicting outcome of hyperacute stroke before thrombolytic therapy. ASPECTS Study Group. Alberta Stroke Programme Early CT Score. Lancet 355:1670-1674

7. Puetz V, Sylaja PN, Coutts SB et al (2008) Extent of hypoattenuation on CT angiography source images predicts functional outcome in patients with basilar artery occlusion. Stroke 39(9):2485-2490

8. van Swieten JC, Koudstaal PJ, Visser MC et al (1988) Interobserver agreement for the assessment of handicap in stroke patients. Stroke 5:604-607

9. Tan IY, Demchuk AM, Hopyan J et al (2009) CT angiography clot burden score and collateral score: correlation with clinical and radiologic outcomes in acute middle cerebral artery infarct. AJNR Am J Neuroradiol 30:525-531

10. Higashida RT, Furlan AJ, Roberts H et al (2003) Technology Assessment Committee of the American Society of Interventional and Therapeutic Neuroradiology; Technology Assessment Committee of the Society of Interventional Radiology: trial design and reporting standards for intra-arterial cerebral thrombolysis for acute ischemic stroke. Stroke 34:109-137

11. Hacke W, Kaste M, Bluhmki E et al (2008) Thrombolysis with Alteplase 3 to 4.5 hours after acute ischemic stroke. N Engl J Med 359:1317-1329

12. Loeffelholz MJ, Tang YM (2020) Laboratory diagnosis of emerging human coronavirus infections. The state of the art. Emerg Microbes Infect 9:747-756

13. Perry RJ, Smith CJ, Roffe C, Simister R, Narayanamoorthi S, Marigold R, Willmot M, Dixit A, Hassan A, Quinn TJ, Ankolekar S, Zhang L, Banerjee S, Ahmed U, Padmanabhan N, Ferdinand P, McGrane F, Banaras A, Marks IH, Werring DJ; SETICOS collaborators (2020) Characteristics and outcomes of COVID-19 associated stroke: a UK multicentre case-control study. J Neurol Neurosurg Psychiatry. jnnp-2020-324927

14. Zhao J, Rudd A, Liu R (2020) Challenges and potential solutions of stroke care during the coronavirus disease 2019 (COVID-19) outbreak. Stroke 51:1356-1357

15. Khosravani H, Rajendram P, Notario L et al (2020) Protected code stroke: hyperacute stroke management during the coronavirus disease 2019 (COVID-19) pandemic. Stroke 51:1891-1895

16. Centers for Disease Control and Prevention: Emergency Medical Services Workers. https://www.cdc.gov/niosh/topics/ems/othlinks. html (Accessed September 18, 2020)

17. Pezzini A, Padovani A (2020) Lifting the mask on neurological manifestations of COVID-19. Nat Rev Neurol 16:636-644

18. Kanberg N, Ashton NJ, Andersson LM (2020) Neurochemical evidence of astrocytic and neuronal injury commonly found in COVID-19. Neurology 95:e1754-e1759

19. Helms J, Kremer S, Merdji H et al (2020) Delirium and encephalopathy in severe COVID-19: a cohort analysis of ICU patients. Crit Care 24:491

20. Beyrouti R, Best JG, Chandratheva A, Perry RJ, Werring DJ (2021) Characteristics of intracerebral haemorrhage associated with COVID-19: a systematic review and pooled analysis of individual patient and aggregate data. J Neurol. https://doi. org/10.1007/s00415-021-10425-9 


\section{Authors and Affiliations}

Alessandro Pezzini ${ }^{1}$ (D) Mario Grassi ${ }^{2} \cdot$ Giorgio Silvestrelli $^{3} \cdot$ Martina Locatelli $^{1,4} \cdot$ Nicola Rifino $^{5,16}$. Simone Beretta ${ }^{5,16} \cdot$ Massimo Gamba $^{6} \cdot$ Elisa Raimondi $^{7}$. Giuditta Giussani ${ }^{8} \cdot$ Federico Carimati $^{9} \cdot$ Davide Sangalli $^{10}$. Manuel Corato ${ }^{11}$. Simonetta Gerevini ${ }^{12}$. Stefano Masciocchi ${ }^{1}$. Matteo Cortinovis ${ }^{1}$. Sara La Gioia ${ }^{13}$. Francesca Barbieri ${ }^{3}$ - Valentina Mazzoleni ${ }^{1}$ - Debora Pezzini ${ }^{1}$. Sonia Bonacina ${ }^{1}$ - Andrea Pilotto ${ }^{1}$ - Alberto Benussi ${ }^{1}$. Mauro Magoni ${ }^{6}$. Enrico Premi ${ }^{6}$. Alessandro Cesare Prelle ${ }^{7}$. Elio Clemente Agostoni ${ }^{8}$. Fernando Palluzzi ${ }^{2}$. Valeria De Giuli ${ }^{4}$. Anna Magherini ${ }^{3}$. Daria Valeria Roccatagliata ${ }^{3} \cdot$ Luisa Vinciguerra $^{4}$ - Valentina Puglisi ${ }^{4}$. Laura Fusi $^{14} \cdot$ Rubjona Xhani $^{14}$. Federico Pozzi ${ }^{14}$. Susanna Diamanti ${ }^{5,16}$. Francesco Santangelo ${ }^{5,16}$. Giampiero Grampa $^{14}$. Maurizio Versino ${ }^{9}$. Andrea Salmaggi ${ }^{10}$. Simona Marcheselli ${ }^{11}$. Anna Cavallini ${ }^{15}$. Alessia Giossi ${ }^{4} \cdot$ Bruno Censori $^{4}$. Carlo Ferrarese ${ }^{5,16} \cdot$ Alfonso Ciccone $^{3} \cdot$ Maria Sessa $^{13}$. Alessandro Padovani ${ }^{1}$ on behalf of the STROKOVID group

1 Department of Clinical and Experimental Sciences, Neurology Clinic, University of Brescia, P.le Spedali Civili, 1, 25123 Brescia, Italy

2 Department of Brain and Behavioural Sciences, Statistics and Genomic Unit, University of Pavia, Pavia, Italy

3 Department of Neurology and Stroke Unit, Carlo Poma Hospital, ASST Mantova, Mantua, Italy

4 Neurology Unit, Istituti Ospitalieri, ASST Cremona, Cremona, Italy

5 Department of Neurology, Ospedale San Gerardo, ASST Monza, Monza, Italy

6 Vascular Neurology, Stroke Unit, Spedali Civili Hospital, ASST Spedali Civili, Brescia, Italy

7 Neurology Unit, Ospedale Nuovo, ASST Ovest Milanese, Legnano, Italy

8 Neurology Unit and Stroke Unit, Department of Neurosciences and Niguarda Neuro Center, ASST Grande Ospedale Metropolitano Niguarda, Milan, Italy
9 Neurology Unit, Ospedale di Circolo e Fondazione Macchi, ASST Sette Laghi, Varese, Italy

10 Neurology Unit, Ospedale “A. Manzoni”, ASST Lecco, Lecco, Italy

11 Emergency Neurology and Stroke Unit, IRCCS Humanitas Clinical and Research Center, Rozzano, Milan, Italy

12 Department of Neuroradiology, Papa Giovanni XXIII Hospital, ASST Papa Giovanni XXIII, Bergamo, Italy

13 Department of Neurology, Papa Giovanni XXIII Hospital, ASST Papa Giovanni XXIII, Bergamo, Italy

14 Neurology Unit, Ospedale "Sant'Anna", ASST Lariana, Como, Italy

15 Stroke Unit, IRCCS Fondazione "C. Mondino", Pavia, Italy

16 Department of Medicine and Surgery and Milan Center for Neuroscience, University of Milano-Bicocca, Milan, Italy 